leges, gained, in large part, by actual experience with students from these colleges, and can give the proper advice in doubtful cases. We have had but little trouble on this score. I myself am inclined to think that the certificates should be passed on by the dean of the university, provided that often overburdened official will take the additional work. In the case of the detached medical schools, however, it is not so easy to answer the question. It is very doubtful if the officials of the public-school systems, to whom this work is now entrusted in many cases, have, in general, sufficient knowledge of the colleges of the country to qualify them for this work. Nor does it appear that the deans of such schools could perform the duty in a satisfactory way, since that knowledge of the work of the colleges derived from years of experience which is found at the universities does not exist there. If, however, there existed some body of definite information concerning the colleges, if certificates giving the detailed information mentioned above be required, and if these certificates were regularly checked by some competent authority, the problem would not be so difficult; and this leads me to make a second suggestion. It seems to me that this Council must add another to its list of achievements. There are many colleges in this country, good, bad and indifferent, about which reliable information accessible to all is very meager. Cannot the Council undertake an investigation of the colleges, as a result of which it could furnish to the medical schools definite information as to which institutions may, and which may not, be safely accredited? This would probably not prove such a formidable task as it may, at first sight, appear. Many of the colleges are well known and require no investigation, reliable judgments of others can be obtained from the deans of the leading universities, and perhaps only a comparatively small number would require personal inspection. Cooperation in this work might be secured with the Association of American Universities, which is now undertaking a classification of American colleges. The results of such an investigation would facilitate immensely the work of administering the requirements re are now discussing, and, incidentally; would be of nuch banefit to the colleges themselves.

(For discussion, see page 87\%)

\section{HOSPITALS AND THEIR RELATION TO MED- ICAL COLLEGES AND THE TRAINING OF INTERNS *}

CHRISTIAN R. HOLMES, M.D.

Dcan of Ohio-Miami Medical Ccllege of the University of Cincinnati CINCINNATI

I realize that it is not alone the buildings of the new hospital and their arrangement which aroused interest and prompted the invitation to me to present to you the illustrations of it, but also the fact that we of Cincinnati have the unique distinction of being the first in this country to possess a strictly municipal university with the medical college an integral part thereof, and a large municipal general hospital, which is the clinical and pathologic school of the medical department - an organization resembling those found in Germany, which I believe we all agree is the best, and which, let us hope

* Read at the Tenth Annual Conference of the Council on Meddeal Education, Chicago, Feb. 24, 1914 is the type that will, in the future, largely be accepted as the standard in this country.

I disclaim any desire to detract in the slightest from the praise due privately endowed or sectarian hospitals, for the splendid service they have rendered and are rendering, and grant that many of them through their fine buildings and superior equipment and excellent teaching facilities were the means of causing (by their example) great improvement in the upkeep and management of municipal institutions; yet, with few exceptions, they are not the type that furnishes the best means for teaching and developing medicine, because in most of them the number of free or charity beds is comparatively limited, and the private or pay patients are usually not at the disposal of the staff for teaching purposes to classes of medical students. Being private institutions, they can elect just what kind of diseases they will or will not admit - infectious and contagious diseases are always excluded. Many of the hospitals

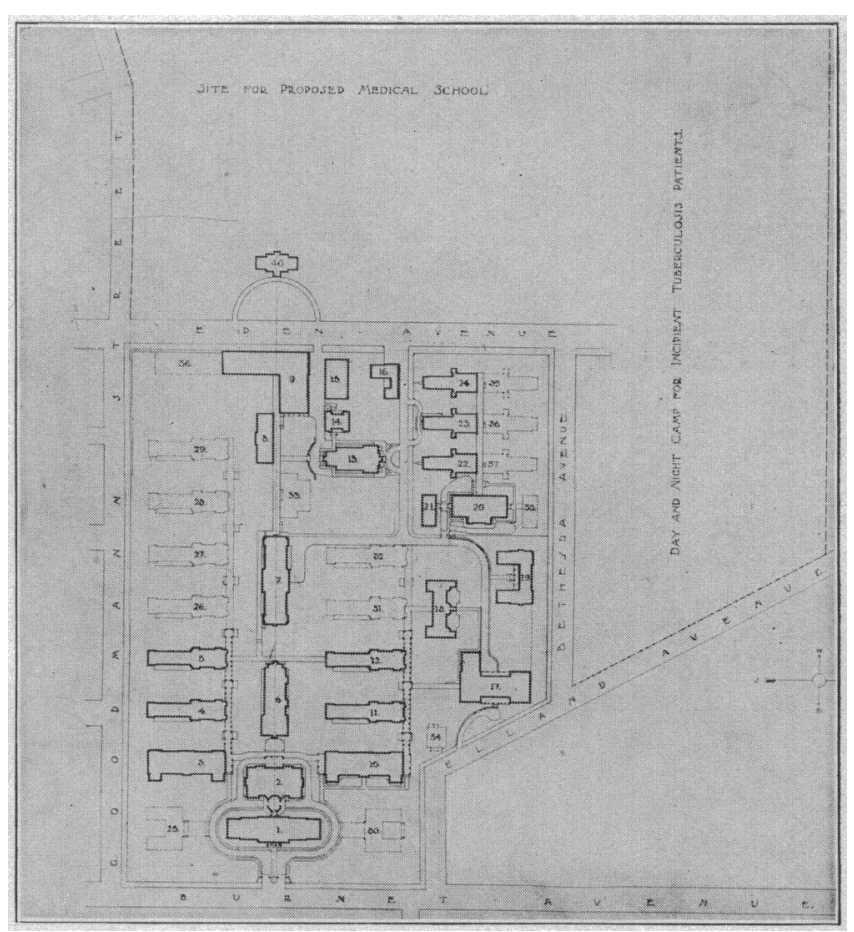

Fig. 1.-Block plan of New General Hospital, Cincinnati; building schedule : 1, administration building; 2 , receiving ward; 3 , Ward $A$; 4, Ward B ; 5, ward C ; 6, operating-pavilion; 7, kitchen and dining-hall; 8, male dormitory and linen-room; 9, power and laundry-bullaing; 10 , Ward $H$; 11 , Ward $; 12$, Ward $K$; 13 , pathologic institute and chapel ; 14, detention ward ; 15, disinfecting station ; 16, garage and stable; 17, nurses' home; 18 , Ward $\mathbf{N} ; 19$, female dormitory ; 20, administration building of contagious group; pay ward; 26 , Ward $\mathrm{D} ; 27$, ward $\mathrm{E} ; 28$, Ward F; 29, Ward G; pay ward; 26, Ward D; 27, Ward $\mathbf{E} ; 28$, Ward F; 29, Ward G; 30, clinic; 31 , Ward L; 32, Ward M; 33 , gymmasium and bathhouse ; 34, suprd $\mathbf{3 7} ; 38$, Ward $\mathrm{S} ; 39$, Ward $T ; 40$, special contagious ward.

siccialize, thus greatly restricting their usefulness to the student. To see all kinds of cases he must visit other hospitals, often far apart. We have continued to crowd more subjects into the student's curriculum until every moment is valuable. Therefore, if the student's work can be concentrated, it will mean conservation of his time and strength and greater efficiency. Nowhere can he obtain that so well as in a large general hospital where all diseases and conditions can be found and freely studied.

In order that all our municipal hospitals shall render the best service, they must not alone care for the sick 
entrusted to them, but also aid in every possible way to broaden our knowledge of how to combat and prevent disease, and that can be accomplished only by making them teaching hospitals.

In Cincinnati the staff positions in the City Hospital are almost exclusively filled by members of the faculty of the medical department of the university. The appointments to the staff have since two years been made by the mayor or his service director on nominations by the staff, but he has the power to disregard their wishes.

A charter commission, elected last year, is now preparing a new charter for Cincinnati, which is to be submitted to the vote of the people this year, and, we hope, will be adopted. This commission is fortunatcly com-
Each of the last four named shall serve for a term of six years. In making the first appointments the mayor shall confirm the selection of the university trustees for a term of six years, and shall appoint one citizen for two ycars, one for four years, and one for six years, and thereafter $c a c h$ of their sucecssors shall be appointed for a term of six years. This board shall have power to appoint such superintcudents as may be necessary and shall have control of the finances and business administration of all hospitals.

To best serve the eitizens of Cincinnati the three objects of the hospitals should ever be kept in mind. The functions. of the eity hospitals are:

A. To care for the sick and injured brought to the city hospitals.

B. To assist in constructive preventive work along the lines of public health and public welfare.

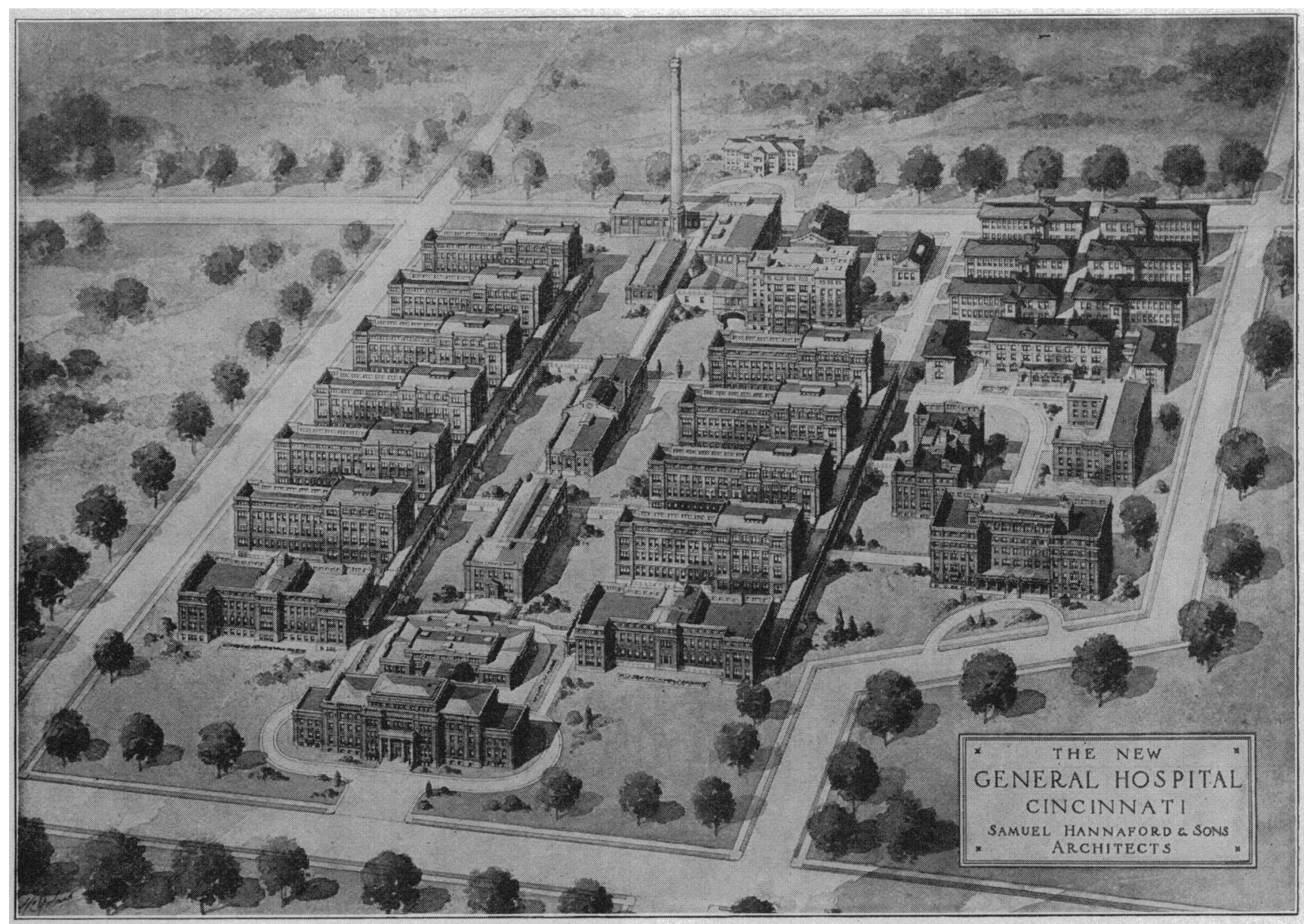

Fig. 2.-Bird's-eye view of the New Gencral Hospital, Cincinnati.

posed of broad-minded men who are fully alive to the best interests of the medical college and the New Hospital, and it may interest you to know how they propose to safeguard both.

The following is copied from the proposed new charter:

First: A Department of Hospitals: This department shall be managed by a board of hospital commissioners of seven members, consisting of the following:

1. The health officer.

2. The director of the Department of Social Welfare.

3. The dean of the medical department of the University of Cincinnati.

4. One person, confirmed by the mayor after selection by the board of trustees of the University of Cincinnati.

5. Thrse citizens to be selected by the mayor.
C. To provide for medical instruction and research.

In order that the new hospital may serve the people of Cincinnati to the fullest extent it must be a teaching hospital, but such teaching facilities shall be open to the students of any medical college in Cincinnati which is recognized by the State Medical Board, and all city hospitals must be closely allied with the medical department of the University of Cincinnati. The university and the hospital are dependent each on the other, and unless the two go forward together neither will measure up to the greatest possible efficiency.

Second: The medical staff of the hospitals shall be appointed by the board of hospital commissioners on the recommendation or nomination of the board of directors of the University of Cincinnati so that the appointments will conform in a large measure to the method of the appointments of professors and instructors in the other departments of the university. 
Third: The medical staff of the hospital shall have tile privileges of teaching and research in the city hospitals. The board of trustees of the university shall determine the manner in which the medical departments of the hospitals shal be organized and conducted to obtain the most efficient service the regulations under which teaching shall be done, and at what stage in their medical course the students shall be admitted to the teaching advantages of the city hospitals.

From this you will see that the medical department of the hospital is placed completely under the jurisdiction of the university, which is, as it should be, while

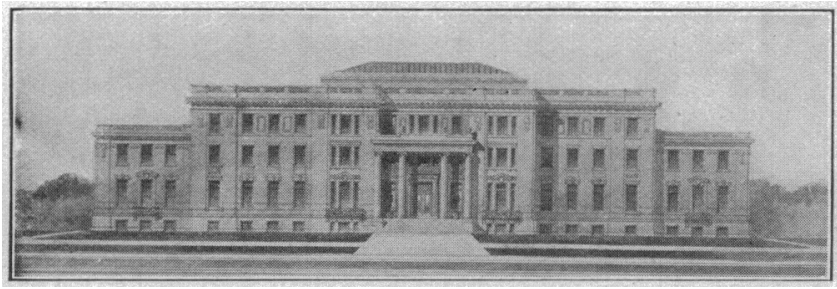

Fig. 3.-Administration building of the New Gencral Hospital, Cincinnati.

the business administration of the hospitals is vested in a board of directors, the composition of which is, I believe, a most effective one.

The board of health in Cincinnati is non-political. This board appoints the health officer (a physician) selected for his ability regardless of his political tenets, and is not subject to the vicissitudes of political changes. Hence we felt that he would be a valuable member on the board.

As a rule, the municipal hospitals in this country have so far devoted themselves only to the care and cure of the sick, but have neglected the social service side, which will look after the families of the patients while the latter are in the hospital, keeping in touch with, following and aiding the convalescent patients after they leave the hospital until they again become breadwinners. It is true that in some instances private social-service organizations have rendered commendable service, but as a rule because of lack of funds and fulltime workers they cannot equal in efficiency a weil-

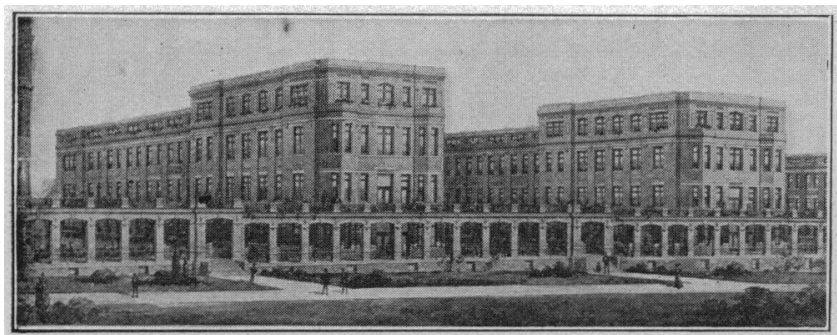

Fig. 4.-Ward buildings of the New General Hospital, Cincinnati

organized and powerful municipal social-service organization. For that reason it was thought well to put the social-service director on the board. The dean of the medical faculty is made a member because, by virtue of his office, he should be in position to give valuable council to the board on medical questions. The other four members will probably be laymen, selected because of their business ability and influence for good in city affairs.

The hospital superintendents and all.employees must pass a civil service examination, which is open to any one whether he resides in or outside of Cincinnati.
We believe that, conducted under such conditions as outlined above, the municipal hospitals in this country will rise to the exalted position which they occupy in Germany, the pride of every city in which they are located, and one of the most potent factors responsiblo for the supremacy of Germany to-day in the world of medicine.

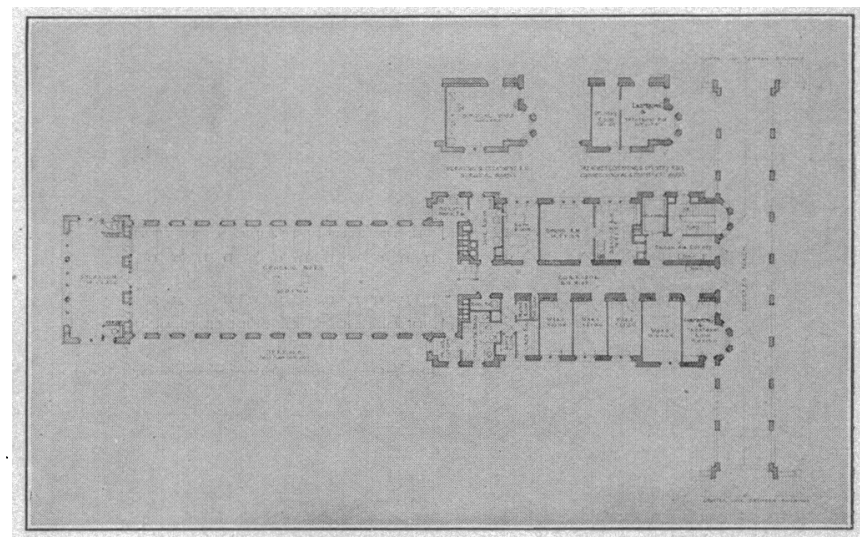

Fig. 5.-First-foor plan, typical ward building, New General Hospital, Cincinnati.

Cincinnati is fortunate in having a mayor who is in full sympathy with this movement. At a dinner given recently in honor of Professor Welch of Johns Hopkins, Mayor Frederick S. Spiegel said in concluding his address of welcome:

In conclusion I desire to say that I am in full agreement with the efforts of our city to establish not merely a hospital but a clinical hospital. To many of our fellow citizens this term may be a strange one, but if they had studied in Vienna or in the cities of Germany, they would know that there the hospital is always a corporate part of the medical school.

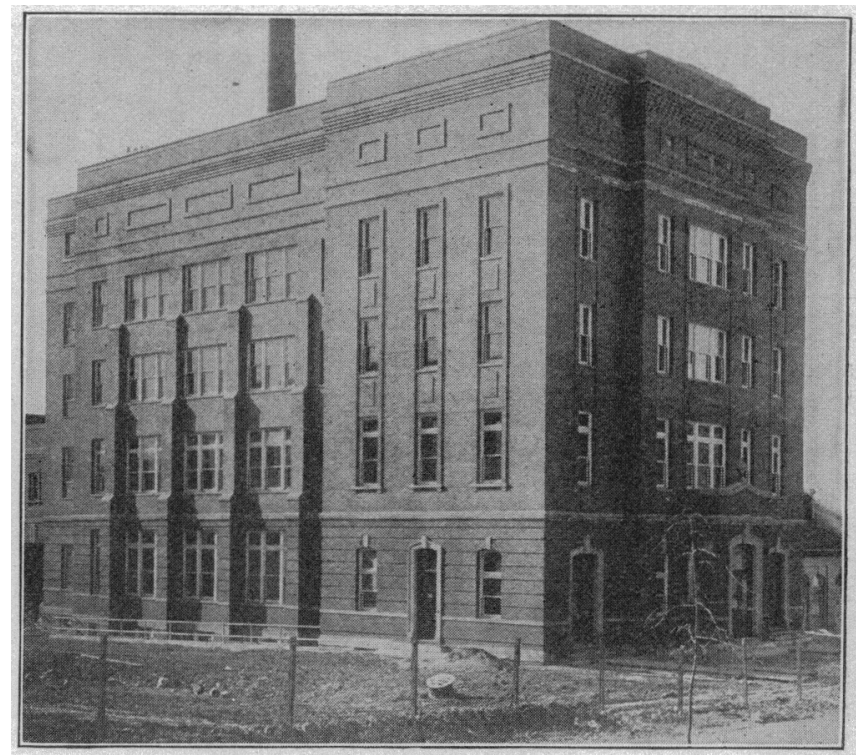

Fig. 6.-Patbologic institute.

Let us hope that the chief executives and those having charge of hospitals in every other large city in this country may be imbued with the same progressive ideas.

Granting then that the large municipal hospitals are the best suited for medical teaching, it becomes our duty to endeavor to raise their medical standard, their organization and administration to the very highest point of 
efficiency. I am strongly in favor of municipal hospitals, because there is no valid reason why the support of the sick poor should fall on the shoulders of the comparatively small number of charitable citizens, which is the case when hospitals are supported by voluntary contributions. The municipal hospitals should be made equal to the best, and their maintenance being paid out
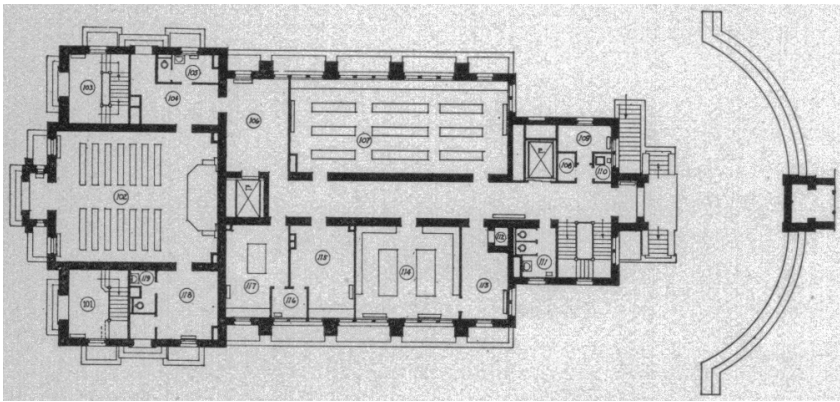

Fig. 7.-First-floor plan, pathologic building, New General Hospital, Cincinnati; schedule of rooms ; 101, stair hall ; 102, chapel; 103, stair hall; 104 , lobby ; 105 , minister's robing-room; 106 , underwater-closet; 112 , vault; 113 , custodian's office ; 114, reading-room 115, chemical laboratory ; 116 , spectroscope; 118 ; family retiring-
room ; 119, water-closet.

of the general taxes will compel that large percentage of the population who are abundantly able to contribute, but never do, to bear their just part of the burden.

I know that the argument will be advanced that politics in city affairs will prevent the carrying out of the high ideals mentioned above. To my mind that depends on the leaders of the profession themselves. If in every city a few of them will stand together and give freely of their time and energy to educate the people as to what is right, and to the best interests of the sick and the city in general, I doubt if there is any community in which the majority of the people will not rally to

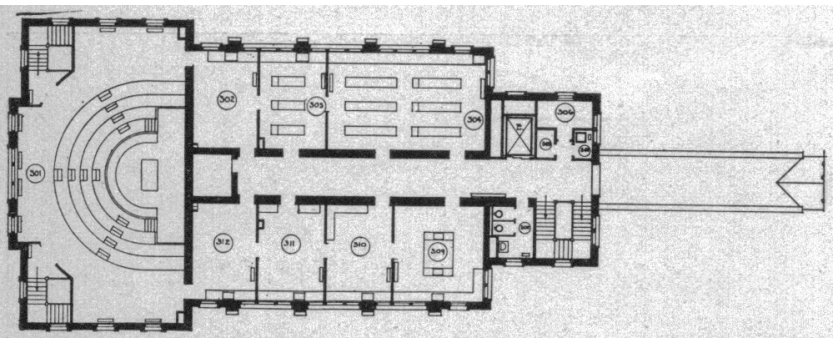

Fig. 8. - Third-floor plan, pathologic building; schedule of rooms ; 301 , amphitheater; $302,303,304,309,310,311,312$, laboratories ; 305, closet ; 307, slop-sink ; 308, water-closet.

their support and help to bring about the desired results. True, it takes time and perseverance, but I am firmly convinced that the old adage that "truth is mighty and will prevail" will clso be proved correct under these conditions.

With the raising of the standard of medical teaching and the hospitals becoming the clinical departments of universities, there must also come, in the interest of hospital efficiency and teaching, the abolition of the rotating service of the chiefs of departments. That this will encounter some opposition there can be no doubt, but it is bound to come, and judging by the number of institutions in which this chan re has been effected, its adoption in the near future by the leading municipal hospitals appears reasonably certain.

The paying of salaries to the heads of the departments of surgery, medicine, obstetrics and gynecology appears to be the best solution. I realize that at present few, if any, public institutions can adopt this standard; but so long as the fundamental branches are taught by firstclass full-time men, the clinical side will, tiil the higher ideal can be accomplished, maintain its standard for efficiency under the guidance of carefully selected practieing physicians who serve without compensation.

In considering how best to regulate the services with payment of salaries to some or all of the heads of departments, we take cognizance of three methods:

1. The heads of all clinical departments shall be paid a salary for devoting a specified amount of time each day to the hospital, but are permitted to carry on their private practice, as is generally done in Germany, certainly with most satisfactory results.

2. The heads of the departments of medicine, surgery, gynecology and obstetrics shall be paid a salary, but are enjoined from carrying on private practice, excepting consultations - the latter not limited to the hospital in which the heads of above-named departments are serving - and for which the physicians retain the fees.

3 . The heads of the departments of medicine, surgery, gynecology and obstetrics shall be paid a salary

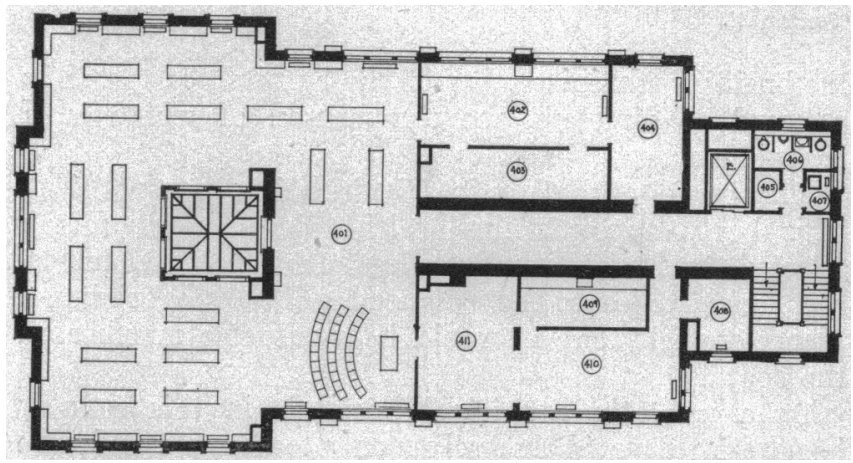

Fig. 9.-Fourth-floor plan, pathologic building; schedule of rooms: 401 , museum ; 402, curator's work-room ; 403 , store-room ; 404, curator's office ; 405 , closet ; 406, water-closet ; 407, slop-sink ; 408 , negative store-room; 409, dark room; 410, photographic laboratory ; 411 , photomicrography.

and their consultations limited to cases brought to their own hospital, with the fees for such consultations going to the hospital fund, instead of to the physician.

My personal views are unhestitatingly in favor of the first proposition.

The wonderful work so successfully performed of investigating, classifying and standardizing the medical schools of this country, as carried out by the Council on

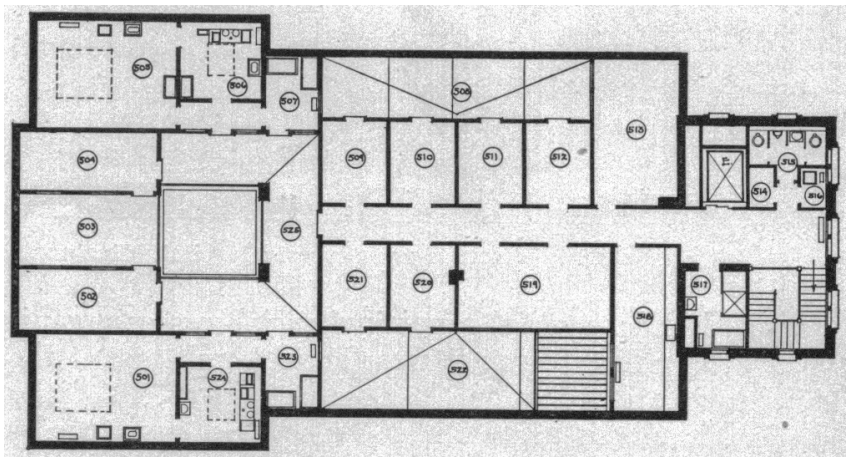

Fig. 10.-Fifth-floor plan, pathologic building; schedule of rooms : 501, surgical operating-room ; 502, 504, 509, 510, 511, 512, 520, 521 , animal pens; $503,508,522$, open yards for animals; 505, pathologic-bacteriologic operating-room; 506, preparation room; $507,517,523$, bath-rooms; 513 , fan room ; 514, closet; $\mathbf{5 1 5}$, water-
closet ; 516, siop-sink; 518, feed room; 519 , store-room; 524 , sterilizing-room; 525, open court.

Medical Education and the Carnegie Foundation, as set forth in Abraham Flexner's classic reports, is rapidly eliminating the undesirable, low-standard medical 
schools. May the work of standardizing the hospitals, which is now under way, be equally successful at an early date. It is perfectly evident that the action already taken by the states of Minnesota, Pennsylvania and others, and the feeling both among leading physicians and among laymen, that every man who is going to practice medicine should have at least one year's service in a hospital, will soon be adopted in many other states. As Dr. Herrick has so aptly said:

If he (the student) does not get his training in this safeguarded manner before he is a licensed practitioner, he is forced to get it in his private practice on your child or on mine with no counseling voice of senior to keep him from sins of omission and commission. How many sad, even fatal blunders, are made through lack of proper practical training no one can tell-it is best not to tell!

I am strongly in favor of the hospital year, and believe that the time has arrived for united action on our part, directed toward having laws passed requiring the hospital year before a license is granted to practice medicine.

If the hospital work is compulsory, then the student has a right to know that the institution he enters is up to the standard requirements. The serving for pay during the hospital year should be prohibited; only poorly conducted institutions will pay, and the small temporary reward can in no way compensate for the loss to the intern of efficient hospital service.

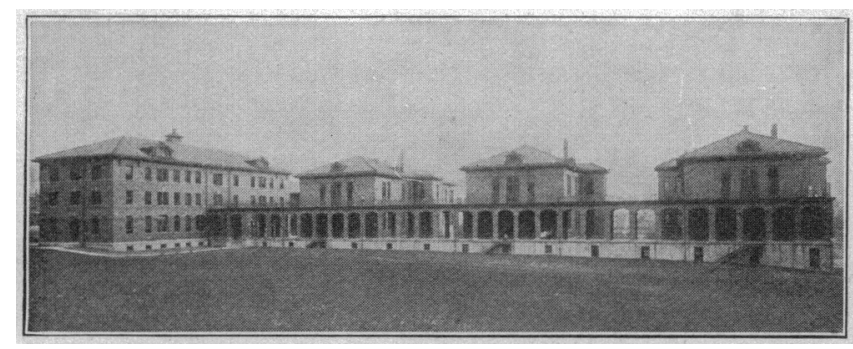

Fig. 11.-Contagious group.

As it was realized several years ago that the hospital year was bound to come, the accommodations for interns in the Cincinnati New General Hospital were planned spacious enough to meet all requirements. According to the comprehensive report of the Council on Medical Education to the House of Delegates, June 16, 1913, on "The Hospital Intern Year," there are in this country about 4,500 medical graduates each year.

There are 924 hospitals having 100 or more beds, and 1,500 having from twenty-five to 100 beds, a total of 2,424 hospitals.

.Of these, 852 hospitals have 3,000 interns, while 1,572 hospitals have no interns, and as there are only 1,500 medical graduates left for whom to provide internships, or less than one intern to every hospital not supplied, there seems no valid reason why there should be any difficulty in providing every candidate with a hospital internship.

Many colleges report that some of their graduates do not desire internships, either because they are going directly into practice or "they were married." One reason for this is no doubt to be found in the fact that, owing to faulty planning, or no planning at all, of the premedical education, the average age of the students graduating in medicine in this country, including a hospital year, is about 28 years, while in England and Germany it is about 25 years.
It therefore seems plain, as so forcibly set forth by Dr. Bevan and others, that the premedical education should be so plarned as to graduate our students at the age of 25 instead of 28 . This would save three years, at that period of life when the fire and ambition of youth with the power of assimilation and adaptability are at their best and count for so much when the graduate is beginning the struggle for an honorable position in his chosen vocation.

(For discussion, see page 87\%)

\section{REGISTRATION UNDER THE CANADA MEDICAL ACT *}

R. W. POWELL, M.D.

Registrar of the Medical Council of Canada OTTAWA, ONT.

Allow me in the first place to express my appreciation of the compliment extended to me in giving me this opportunity of addressing this distinguished gathering of educationalists. I fully realize that it is the office I hold that has singled me out for this distinction, but nevertheless, I feel that you will pardon an humble pride when I tell you that this scherne of "Dominion Registration" has for many years been very dear to my heart and that in season and out of season I have forwarded the measure to the limit of my capacity, and now when $I$. find that within eighteen months of its fruition I am here in the flesh to amplify its measures to my colleagues of this great republic, I feel a sense of gratification not measurable in words.

Since the birth of the Dominion of Canada in 186\% the profession of medicine has never once lost sight of the unfortunate position it was placed in by reason of certain clauses of the British North America act, which placed matters affecting education under the control of the provinces. It is fairly clear that such was not the absolute intention of the framers of that act; but rather that what was intended to be included was matters of ordinary or common public education, and from that day to this the provinces have held out stoutly. for what they honestly believed were their rights under the constitution.

With the birth of the Dominion came the birth of the Canada Medical Asscciation, and at its first session in Quebec in 1867 under the presidency of Dr. Tupper, now the veteran Sir Charles Tupper, the question was introduced and discussed and a bill was actually framed about two years later to tect the question in the Canadian parliament. So many obstacles appeared to be in the way that the scheme was dropped so far as the active political leaders were concerned. When I mention that Sir Charles Tupper, a prominent member of our profession in his day and a prominent and leading politician as well, felt that the scheme for a federal act was out of the question, you will realize that serious difficulties must have been on the horizon. Sir Charles was not a man to be daunted by trifles and he was always the embodiment of loyalty to our profession.

I may add that years afterward (in the early eighties) I personally went into the matter with him, only to be told that the one and only way to accomplish our desires was by first securing an amendment to the

- Read at the Tenth Annual Conference of the Council on Medical Education, Chicago, Fcb. 24, 1914. 